\title{
Cushing's syndrome and adrenal insufficiency after intradermal triamcinolone acetonide for keloid scars
}

\author{
Martijn J. J. Finken • Dick Mul
}

Received: 11 January 2010 / Accepted: 4 February 2010 /Published online: 26 February 2010

(C) Springer-Verlag 2010

\begin{abstract}
A 6-year-old girl was admitted to our hospital for excessive weight gain. On presentation, she had a typical Cushingoid appearance and hypertension. Laboratory analysis was indicative for an exogenous glucocorticoid source, showing values that were low for serum cortisol and adrenocorticotropin and for 24-h urinary glucocorticoid (metabolite) excretion. Five and 2 months before presentation, she was treated with intradermal triamcinolone acetonide for keloid scars. Recovery of intrinsic cortisol production occurred 12 months after the last steroid dose. Intradermal triamcinolone acetonide for keloid scars in children should be used with care taking into account the here reported complication.
\end{abstract}

Keywords Adrenal insufficiency · Cortisol .

Cushing's syndrome $\cdot$ Triamcinolone acetonide

\section{Introduction}

Long-term glucocorticoid treatment is known to cause Cushing's syndrome and adrenal insufficiency. Here, we present a child who developed these conditions after two

\section{J. J. Finken $(\bowtie) \cdot D$. Mul}

Department of Pediatrics, Leiden University Medical Center, P.O. Box 9600, 2300 RC Leiden, The Netherlands

e-mail: m.finken@vumc.nl

M. J. J. Finken

Department of Pediatrics, VU Medical Center,

P.O. Box 7057, 1007 MB Amsterdam, The Netherlands

D. Mul

Department of Pediatrics,

Haga Teaching Hospital/Juliana Children's Hospital,

Sportlaan 600

2566 MJ Den Haag, The Netherlands treatment courses with normal amounts of triamcinolone acetonide (TCA) administered intradermally in another hospital for keloid scars. As the parents were reassured that this treatment was without any side effects, they did not mention it instantly when their daughter was evaluated in our center for excessive weight gain a few months later.

\section{Case report}

A 6-year-old previously healthy girl was seen at our outpatient department because of excessive weight gain $(3 \mathrm{~kg}$ in the past 3 months), despite a virtually normal intake and unchanged physical exercise according to the parents. There was no medication use. Height development in infancy and childhood had always been around the 50th percentile. All family members were in good health, except for an older brother who had undergone a bone marrow transplantation a few years ago because of homozygous beta-thalassemia.

On physical examination, she had a moon face (Fig. 1), a central pattern of fat distribution, and a blood pressure of 118/85 mmHg (both $>95$ th percentile). There were (remains of) keloid scars in the lower abdominal region and in the left loin ( $2 \%$ to $3 \%$ of her body surface area), which had appeared after a hot water burn. Her height was $117.3 \mathrm{~cm}$ (-0.1 SD), and her weight was $24.4 \mathrm{~kg}(+1.3 \mathrm{SD})$.

Laboratory tests showed a normal thyroid function. Serum cortisol and adrenocorticotropin (ACTH), which were measured in the morning after overnight fasting, were below detection limits (normal $0.100-0.600 \mu \mathrm{mol} / 1$ and 15 $75 \mathrm{ng} / \mathrm{l}$, respectively). Sodium, potassium, and glucose were all normal. Urinary free cortisol excretion was $5 \mathrm{nmol} /$ $24 \mathrm{~h}$ (normal 55-220 nmol/24 h). Glucocorticoid metabolites in 24-h urine obtained on one occasion were undetectable. Salivary cortisol levels were low, and diurnal 

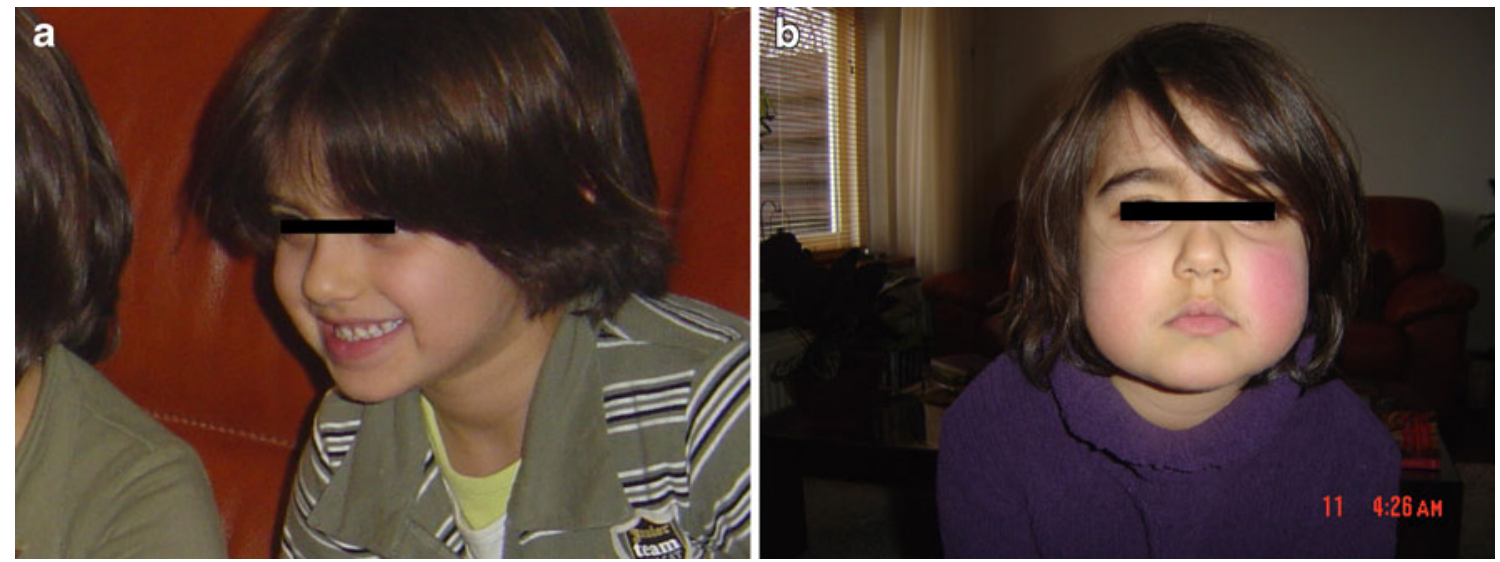

Fig. 1 Facial appearance of our patient. a Just before TCA treatment. b Six months after the first TCA dose

rhythmicity was absent. These laboratory findings were indicative for an exogenous glucocorticoid source.

Accidental steroid exposure was unlikely, since there was no glucocorticoid use for post-bone marrow transplantation by her older brother. Steroid use by the other family members was also reported to be negative. Subsequently, the parents were asked to describe their daughter's medical history in detail. They told that in another hospital, injections had been given into the keloid scars on two occasions. Information retrieved from that hospital revealed that 5 months prior to the initial presentation, she was treated with $160 \mathrm{mg}$ of TCA, and 2 months before the first visit, she was given $40 \mathrm{mg}$ of TCA in spite of concerns by the parents of increasing puffiness.

Ten months after the first injection, serum levels of cortisol and ACTH, obtained in the morning, were $0.090 \mu \mathrm{mol} / \mathrm{l}$ and $18 \mathrm{ng} / \mathrm{l}$, respectively. Continuing suppression of the hypothalamus-pituitary-adrenal axis was subsequently confirmed with a low-dose ACTH test (tetracosactide $1 \mu \mathrm{g}$ per $1.73 \mathrm{~m}^{2}$ body surface area), during which, the serum cortisol level rose from 0.040 to $0.190 \mu \mathrm{mol} / \mathrm{l}$. Cushingoid features became less apparent 13 months after the first injection. At the same time, it was noted that height velocity, which had dramatically declined since the first presentation, had started to increase again. Fifteen months after the first injection, the hypothalamuspituitary-adrenal axis had finally recovered: cortisol increased from 0.103 to $0.538 \mu \mathrm{mol} / \mathrm{l}$ during the low-dose ACTH test. Until recovery of intrinsic cortisol production had occurred, the parents were instructed to give hydrocortisone in case of febrile illnesses or moderate injury.

\section{Discussion}

Cushing syndrome is caused by excessive circulating cortisol levels and is characterized by a changed facial appearance, abdominal fat deposition, muscle weakness, striae, hirsutism, insulin resistance, and hypertension. Pediatric Cushing's syndrome is caused by ACTH producing pituitary adenoma (Cushing's disease) in $75-80 \%$ of cases [7]. The median age of these patients is 14 years. Less frequent are adrenocortical tumors or other causes leading to hypercortisolism, such as the ectopic ACTH syndrome or adrenal hyperplasia secondary to McCune-Albright syndrome. There are no quantitative data available as to which extent synthetic steroids contribute to the incidence of Cushing's syndrome in the pediatric age range.

In this report, we describe a 6-year-old child who developed Cushing's syndrome after intradermal injections with TCA. Triamcinolone is a synthetic steroid which differs from cortisol mainly in 9-alpha fluoridation. Due to this chemical structure, it acts as a potent glucocorticoid. The anti-inflammatory effect of triamcinolone is five times as potent as that of endogenous cortisol. Contrary to cortisol, it has no affinity for the mineralocorticoid receptor. So, the hypertension observed in our patient had resulted from glucocorticoid receptor-mediated effects on the vascular tone rather than from mineralocorticoid receptordriven sodium retention. She was treated with $200 \mathrm{mg}$ of TCA. This dose is equal to only 3 months of intrinsic cortisol production (at a mean rate of $12 \mathrm{mg} / \mathrm{m}^{2} / 24 \mathrm{~h}$ ). Comparable steroid doses are often given for an acute asthma exacerbation [8].

It has been tested in a sample of 22 children with chronic arthritis that suppression of intrinsic cortisol production, assessed by salivary cortisol concentration, may last 10 to 30 days after an intra-articular injection with triamcinolone hexacetonide (THA) [2]. None of the children in this group had developed a Cushingoid state. In contrast, Cushing's syndrome after intra-articular TCA has been described by several reports in adults [3,5] and children [1, 4]. A retrospective analysis comparing TCA with THA in children with juvenile idiopathic arthritis showed that 5\% 
had developed a Cushingoid appearance after intra-articular TCA, whereas nobody had developed this after THA [1].

For our patient, it is conceivable that the keloid scars might have served as a "slow release reservoir," probably due to poor absorption and vascularization locally. A mild manifestation of Cushing's syndrome has been described in two children who were treated with TCA for post-burn hypertrophic scars [6]. To date, Cushing's syndrome with prolonged adrenal suppression has been described in two children who were treated with TCA for keloid scars [4, 9]. One of these patients had received 500-600 mg of TCA [4], while the other had received only $40 \mathrm{mg}$ of TCA [9]. In these patients, adrenal suppression was still present 8 to 9 months after intralesional TCA injection, but recovery of intrinsic cortisol production was not reported by the papers. In our patient, adrenal suppression was present up to 15 months after the first steroid dose. Suppression of intrinsic cortisol production is potentially fatal under circumstances where the physiological demand for cortisol exceeds the ability of the adrenal glands to produce it, such as febrile illnesses, trauma, or surgery.

TCA should be used with care for keloid scars in children, now evidence is accumulating that even a relatively low dose of intradermal TCA may elicit Cushing's syndrome and prolonged adrenal suppression. We recommend that TCA should not be part of the routine treatment of keloid scars in children. TCA should only be considered in case of problematic keloid scars (e.g., severe cosmetic problems or contractures).
Conflict of interest statement None.

\section{References}

1. Gondwe JS, Davidson JE, Deeley S et al (2005) Secondary Cushing's syndrome in children with juvenile idiopathic arthritis following intra-articular triamcinolone administration. Rheumatology 44:1457-1458

2. Huppertz HI, Pfüller H (1997) Transient suppression of endogenous cortisol production after intraarticular steroid therapy for chronic arthritis in children. J Rheumatol 24:1833-1837

3. Jansen TL, van Roon EN (2002) Four cases of a secondary Cushingoid state following local triamcinolone acetonide (Kenacort) injection. Neth J Med 60:151-153

4. Kumar S, Singh RJ, Reed AM, Lteif AN (2004) Cushing's syndrome after intra-articular and intradermal administration of triamcinolone acetonide in three pediatric patients. Pediatrics 113:1820-1824

5. O'Sullivan MM, Rumfeld WR, Jones MK, Williams BD (1985) Cushing's syndrome with suppression of the hypothalamuspituitary-adrenal axis after intra-articular steroid injections. Ann Rheum Dis 44:561-563

6. Ritota PC, Lo AK (1996) Cushing's syndrome in post-burn children following intralesional triamcinolone injection. Ann Plast Surg 36:508-511

7. Savage MO, Chan LF, Afshar F et al (2008) Advances in the management of paediatric Cushing's disease. Horm Res 69:327333

8. Smith M, Iqbal SM, Rowe BH, N'Diaye T (2003) Corticosteroids for hospitalised children with acute asthma. Cochrane Datab Syst Rev. doi:10.1002/14651858

9. Teelucksingh S, Balkaran B, Ganeshmoorthi A, Arthur P (2002) Prolonged childhood Cushing's syndrome secondary to intralesional triamcinolone acetonide. Ann Trop Paediatr 22:89-91 